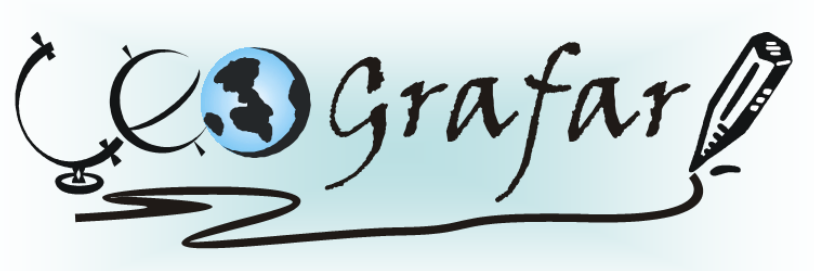

Revista Eletrônica do Programa de Pós-Graduação em Geografia - UFPR

\title{
HEMEROBIA E PLANEJAMENTO DA PAISAGEM NO BAIRRO MOSSUNGUÊ, CURITIBA - PR
}

\section{HEMEROBY AND LANDSCAPE PLANNING IN THE MOSSUNGUÊ DISTRICT, CURITIBA - PR}

\section{(Recebido em 18.05.2014; Aceito em: 20.06.2014)}

Ângela Dileta Lima Santa Barbara Geógrafa

Universidade Federal do Paraná Curitiba, PR, Brasil e-mail: angela_lima09@yahoo.com.br

Simone Valaski

Prof. Dra. do Setor de Educação

Profissional e Tecnológica

Universidade Federal do Paraná

Curitiba, PR, Brasil

e-mail: simonevalaski@ig.com.br

João Carlos Nucci

Prof. Dr. do Departamento de Geografia

Universidade Federal do Paraná

Curitiba, PR, Brasil

e-mail:nucci@ufpr.br

\begin{abstract}
RESUMO
Hemerobia pode ser entendida como a dependência energética e tecnológica para a manutenção da paisagem. Paisagens com a mais baixa hemerobia são as que apresentam capacidade de auto regulação, sem influência humana direta e as de mais alta hemerobia são aquelas criadas pelo ser humano e caracterizadas pelo intenso domínio de estruturas e processos técnicos. Medidas que classificam e ordenam as paisagens para que tenham uma menor hemerobia colaboram para a solução dos problemas oriundos da atual crise ambiental. O objetivo do trabalho foi o de classificar as paisagens do bairro Mossunguê (Curitiba, PR) segundo graus de
\end{abstract}


hemerobia. As unidades de paisagens do bairro foram identificadas e mapeadas com base nas estruturas (cobertura do solo), das paisagens; inferências foram feitas sobre suas dinâmicas e as unidades de paisagens foram avaliadas de modo relativo segundo os graus de hemerobia. Foram utilizadas imagens de satélite, do ano 2010 e na escala aproximada 1:5.000 obtidas no Google Earth e base cartográfica, do ano 2012 e na escala 1:20.000, do Instituto de Pesquisa e Planejamento Urbano de Curitiba (IPPUC). O bairro apresentou $74,4 \%$ de sua área com hemerobia de mínima a média (com cobertura vegetal e edificações abaixo de 4 pavimentos e, somente, $25,6 \%$ com hemerobia alta, muito alta e máxima (com edificações acima de 4 pavimentos e com pouca vegetação), o que confere ao bairro uma ótima condição ambiental, porém, com riscos de aumento da hemerobia devido ao processo de adensamento e de verticalização das edificações.

Palavras-Chave: Planejamento da Paisagem, qualidade ambiental, unidades de paisagem, ecologia urbana.

\begin{abstract}
Hemeroby can be understood as the energy and technological dependency for landscape maintenance. Landscapes with lowest hemeroby have capacity to selfregulation without direct human influence and the higher hemeroby are those created by human beings and they are characterized by intense domain of structures and technical processes. A contribution to solve the problems caused by current environmental crisis is the classification and organization of the landscapes so that they have lower hemeroby. The purpose of this paper was to classify the landscapes of Mossungue district (Curitiba-PR) according to hemeroby degrees. It was identified and mapped the landscapes units of the district based on the landscapes structure (land cover); inferences were made about its dynamics and the landscapes units were valued according the hemeroby degrees. It was used satellite images, 2010, scale 1:5.000, from Google Earth and cartographic basis, 2012, scale 1:20.000, from IPPUC (Instituto de Pesquisa e Planejamento Urbano de Curitiba). The district has $74,4 \%$ of its area with hemeroby between minimum and avaragen (vegetation cover buildings below 4 stories) and, only $25,6 \%$ with high hemeroby, very high hemeroby and maximum hemeroby (buildings above 4 stories and little vegetation). These results show that the district has a great environmental condition, but with a risk of the hemeroby increase caused by increase of urban density and the verticalization process.
\end{abstract}

Keywords: Landscape planning, environmental quality, landscape units, urban ecology. 


\section{INTRODUÇÃO}

Desde os seus primórdios os seres humanos vem adquirindo cada vez mais uma grande capacidade de transformar as paisagens.

Ross (2009) afirma que atualmente não existem ecossistemas não modificados pelo homem, o que difere é a natureza e a importância que estas modificações causam no meio ambiente. Monteiro (1978), que utiliza o termo "Derivações Antropogênicas" para explicar as alterações feitas pelo homem na paisagem, afirma que essas modificações podem ser qualificadas como positivas ou negativas.

Para $\circ$ julgamento se as derivações antropogênicas são positivas ou negativas, seria necessário um conjunto de critérios e parâmetros. Um conceito que vem sendo utilizado para qualificar as alterações que o ser humano provoca na paisagem é o de hemerobia.

Jalas (1955 ${ }^{1}$ apud TROPPMAIR, 2008) classificou a Hemerobia de acordo com a interferência humana e em quatro classes: Ahemeorobio (ecossistemas naturais ou com pequena interferência humana; Oligohemeorobio (ecossistemas mais naturais do que artificiais, com pouca interferência humana); Mesohemeorobio (ecossistemas mais artificiais, com maior interferência humana do que o oligoheorobio); Euhemeorobio (ecossistemas artificiais, com interferência humana, como áreas de cultivo agrícola).

Sukopp (1972) conceitua o termo hemerobia como a totalidade dos efeitos do ser humano na paisagem/ecossistema, classificando a paisagem de acordo com os graus de naturalidade, ou seja, uma paisagem terá baixo grau de hemerobia quanto mais natural ela for, e terá maior grau de hemerobia quanto mais antropizada ela for.

Portanto, para esses autores, hemerobia está relacionada com o grau de interferência do ser humano na paisagem, chegando a classificar as paisagens segundo o grau de naturalidade.

Odum (1983), diferentemente dos anteriores e sem utilizar o termo hemerobia, propõe uma classificação de ecossistemas baseada segundo a fonte e o

1 JALAS, J. 1955: Hemerobe und hemerochore Pflanzenarten. Ein terminologischer Reformversuch. Acta Soc. Fauna Flora Fen. 72 (11): 1-15 
nível de energia necessários para a manutenção de uma paisagem, classificando-os em quatro classes: ecossistemas naturais que dependem da energia solar, sem outros subsídios (ex.: oceanos, florestas de altitude); ecossistemas naturais que dependem da energia solar, com subsídios de outras fontes naturais de energia (ex.: florestas úmidas, estuários de marés); ecossistemas que dependem da energia solar, com subsídios antropogênicos (ex.: agricultura, aquacultura); sistemas urbanoindustriais, movidos a combustível (ex.: cidades, bairros residenciais e zonas industriais).

Haber (1990) propõe uma classificação dos ecossistemas, porém, também, sem utilizar o termo hemerobia. $O$ autor classifica os ecossistemas conforme os tipos de usos da terra, ou seja, de acordo com a dependência tecnológica e energética dos sistemas, classificando-os em bio-ecossistemas e tecno-sistemas, sendo o primeiro grupo subdividido em: ecossistemas naturais (com capacidade de autorregulação, sem influência humana direta); ecossistemas próximos ao natural (com capacidade de autorregulação, porém sofre influência humana); ecossistemas seminaturais (formados pelo ser humano, sendo resultado de sua ação sobre os ecossistemas citados anteriormente, possuindo mínima capacidade de autorregulação); e o ecossistema (biótico) antropogênico (criado pelo ser humano e totalmente dependente do controle e manejo). Os tecno-sistemas, definidos por Haber (1990), são aqueles criados pelo ser humano, os quais são caracterizados pelo domínio de estrutura e processos técnicos, sendo exemplo destes os ambientes com desenvolvimento de atividades industriais, econômicas ou culturais.

Tanto Odum (1983) quanto Haber (1990), apesar de ainda utilizarem o termo "natural", enfatizam a questão na dependência energética e tecnológica da paisagem.

Porém, segundo Belem e Nucci (2011), a maioria dos autores que trabalha com o conceito de hemerobia ou com o grau de dependência energética e tecnológica dos ecossistemas, ignora o interior das cidades, propondo estudos apenas em escalas pequenas e, portanto, impróprias para a análise das diferentes paisagens encontradas em áreas urbanizadas.

Em se tratando de paisagens urbanizadas, Hough (1995) as classifica em dois tipos: formal e natural. Para esse autor a paisagem formal apresenta pouca conexão com a dinâmica dos valores naturais, é considerada como uma expressão 
de esmero, estética e civismo, requerendo muita energia e uso de tecnologia, engenharia e horticultura, com um desenho padrão independentemente do lugar, podendo ser encontrada em qualquer parte; já a paisagem natural representaria a vitalidade dos processos naturais e sociais que, mesmo alterados, atuam na cidade, mas, que apesar disso, é considerada, pela maioria, como terreno baldio abandonado, necessitando de renovação urbana.

É importante lembrar que ao modificar a paisagem, as inserções humanas não modificam as leis da natureza, elas interferem nos fluxos de energia e matéria, forçando a natureza a encontrar novos pontos de equilíbrio (ROSS, 2009). Deste modo "as sociedades humanas não devem ser tratadas como elementos estranhos à natureza e aos ambientes onde vivem, mas precisam ser vistas como parte fundamental dessa dinâmica de fluxos energéticos que fazem funcionar o sistema" (ROSS, 2009, p. 54).

Sendo assim, é de fundamental importância considerar a estrutura, a dinâmica e a evolução da natureza, mesmo em paisagens muito transformadas pelos seres humanos, como as urbanizadas.

Nesse aspecto, o Planejamento da Paisagem, instrumento previsto em lei na Alemanha, vem auxiliando nas medidas de orientação preventiva em relação à conservação da natureza, mesmo em paisagens urbanizadas (KIEMSTEDT et al,1998).

O Planejamento da Paisagem é um instrumento que visa salvaguardar a capacidade funcional dos ecossistemas e a forma das paisagens de um modo sustentável e duradouro, em áreas urbanizadas ou não, como partes fundamentais para a vida humana. A conservação da natureza e o uso da natureza de um modo compatível com o meio ambiente pode produzir uma considerável contribuição na direção da implementação de um desenvolvimento sustentável (KIEMSTEDT et al,1998).

As principais metas do Planejamento da Paisagem são (KIEMSTEDT et al,1998): salvaguardar a biodiversidade por meio de interligações de áreas protegidas, naturalização de cursos d'água, florestamento, etc.; salvaguardar as paisagens, seus elementos e os espaços livres para fornecer a oportunidade de contato contemplativo e recreativo na natureza; salvaguardar o solo, a água e o clima por meio da regulamentação de seus usos e regeneração dos recursos e; 
definir recomendações sobre a qualidade da natureza e das paisagens, e metas de qualidade ambiental como subsídio à Avaliação de Impactos Ambientais.

Valaski (2013), aplicando os princípios do Planejamento da Paisagem (KIEMSTEDT et al,1998) e os critérios de avaliação da qualidade ambiental urbana ( $\mathrm{NUCCl}, 2008$ ), desenvolveu um método que considera a estrutura da paisagem para se inferir a dinâmica e a qualidade ambiental dos diferentes tipos de unidades de paisagens urbanizadas. A autora analisou um transecto norte-sul no município de Curitiba, identificando a cobertura do solo (estrutura da paisagem) e organizou os tipos de paisagens encontrados em uma chave classificatória que apresenta as inferências em relação à dinâmica, ou seja, aos processos que podem estar ocorrendo em cada paisagem.

O presente artigo apresenta uma aplicação no bairro Mossunguê (Curitiba, PR) do método desenvolvido por Valaski (2013) e, sobre as paisagens identificadas no bairro, aplica o conceito de hemerobia, assim, analisando o grau de dependência energética e tecnológica (HABER, 1990) com base na estrutura e dinâmica dos diferentes tipos de paisagens.

O bairro Mossunguê, nas últimas duas décadas, vem se transformando rapidamente de um bairro com presença de muita cobertura vegetal, para um bairro com presença de um grande corredor de edifícios, entremeados por condomínios de alta classe e favelas, além de supermercado, shopping e postos de combustíveis. As mudanças ocorridas no bairro devem-se principalmente ao status a ele atrelado, ou seja, um bairro que sofre alterações principalmente para atender a classe alta da sociedade curitibana, que busca nos condomínios construídos recentemente uma boa qualidade de vida.

\section{MÉTODO}

Conforme o IPPUC (2005), o bairro Mossunguê ${ }^{2}$, é delimitado pela Rua José Izidoro Biazetto, seguindo marginal da BR-277 até encontrar o Rio Barigui, depois segue por linha seca até chegar à rua João Alves de Deus, encontra o rio Mossunguê, novamente segue por linha seca até a rua Jeremias Maciel Perretto,

${ }^{2}$ Mossunguê, do tupi, "Moçym-ghê, os mussuns, ou enguias do Brasil." (SAMPAIO, 1987, p. 287) 
continua na rua João Batista Rossetim, encontra a rua Francisco Juglair, segue desta até a rua Domingas Nicco, e desta encontra a rua Pedro Nicco até chegar novamente à rua José Izidoro Biazetto (Figura 1).

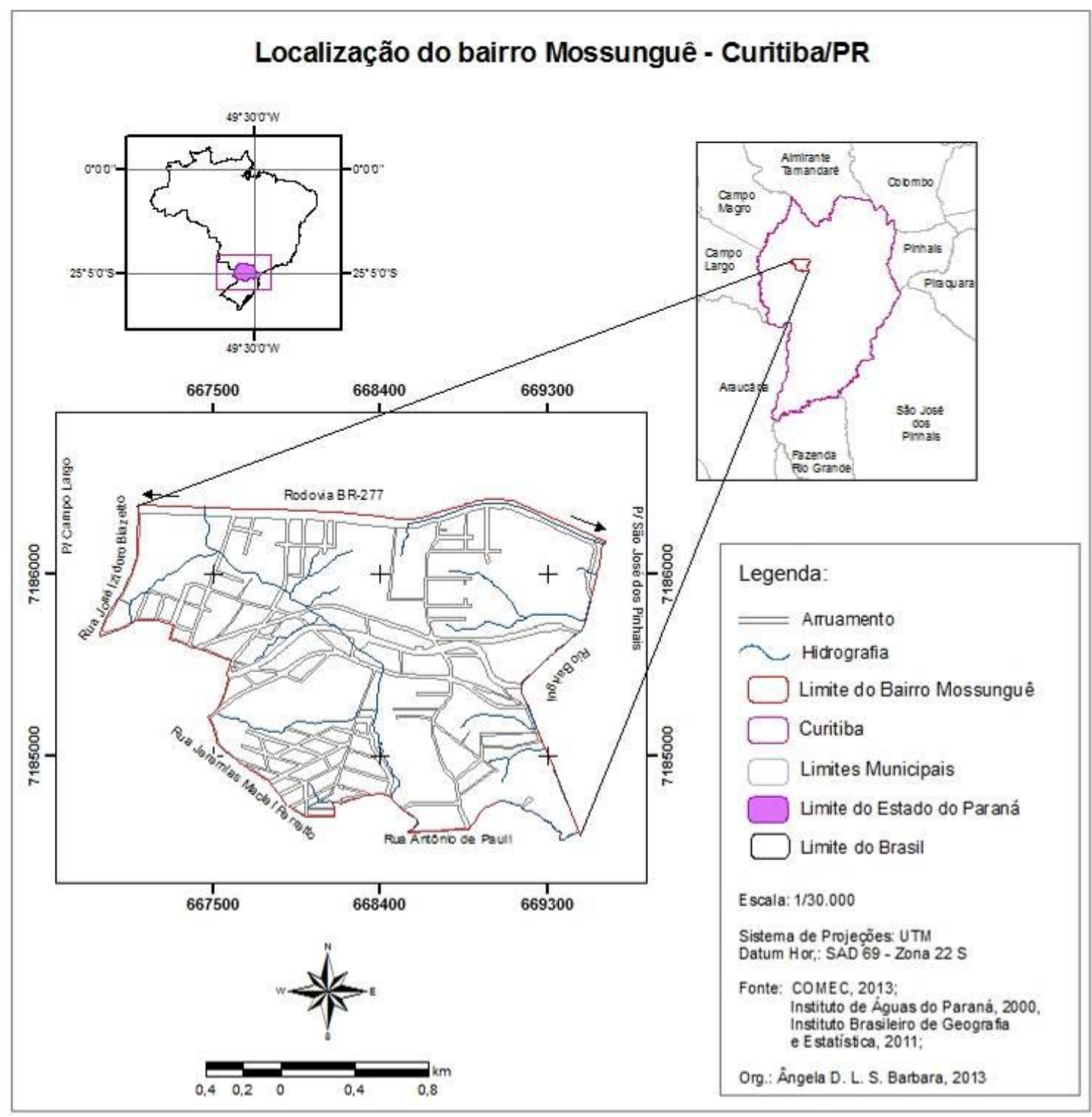

Figura 1: Localização da área de estudo.

Com base na imagem de satélite georeferenciada do Google Earth, escala 1:5.000 e ano de 2010, foram mapeadas, com a utilização do software Arcmap ${ }^{\circledR}$ da ESRI e sobre a base de dados de arruamento disponibilizada pelo IPPUC, na escala 1:20.000 do ano de 2012, as unidades de paisagem no bairro Mossunguê e organizada a chave classificatória, de acordo com o método desenvolvido por 
Valaski (2013). As fotos da chave classificatória, para a caracterização da legenda, foram obtidas por meio do Google Street View.

Ressalta-se a utilização do sistema geodésico de referência SIRGAS 2000, pois de acordo com as novas especificações técnicas do IBGE (2013), até o ano de 2014 as bases cartográficas devem ser alteradas para este sistema de referência, por isso, tanto o mapa de Classificação das Unidades de Paisagem, e também o mapa de classificação de Hemerobia do bairro Mossunguê foram confeccionados neste sistema geodésico de referência.

Com base nos dados do mapeamento das unidades de paisagem, foi feito um novo mapeamento, desta vez, das classes de hemerobia, de acordo com as classes elaboradas por Belem e Nucci (2011).

Optou-se por agrupar algumas classes de unidades de paisagem em uma única classe de hemerobia, pois estas possuem características semelhantes.

\section{RESULTADOS E DISCUSSÃO}

A Figura 2 apresenta o mapa dos diferentes tipos de cobertura do solo e a Figura 3 a chave classificatória que descreve a estrutura e a dinâmica de cada tipo de cobertura. 
Hemerobia e Planejamento da Paisagem no bairro Mossunguê, Curitiba - PR.

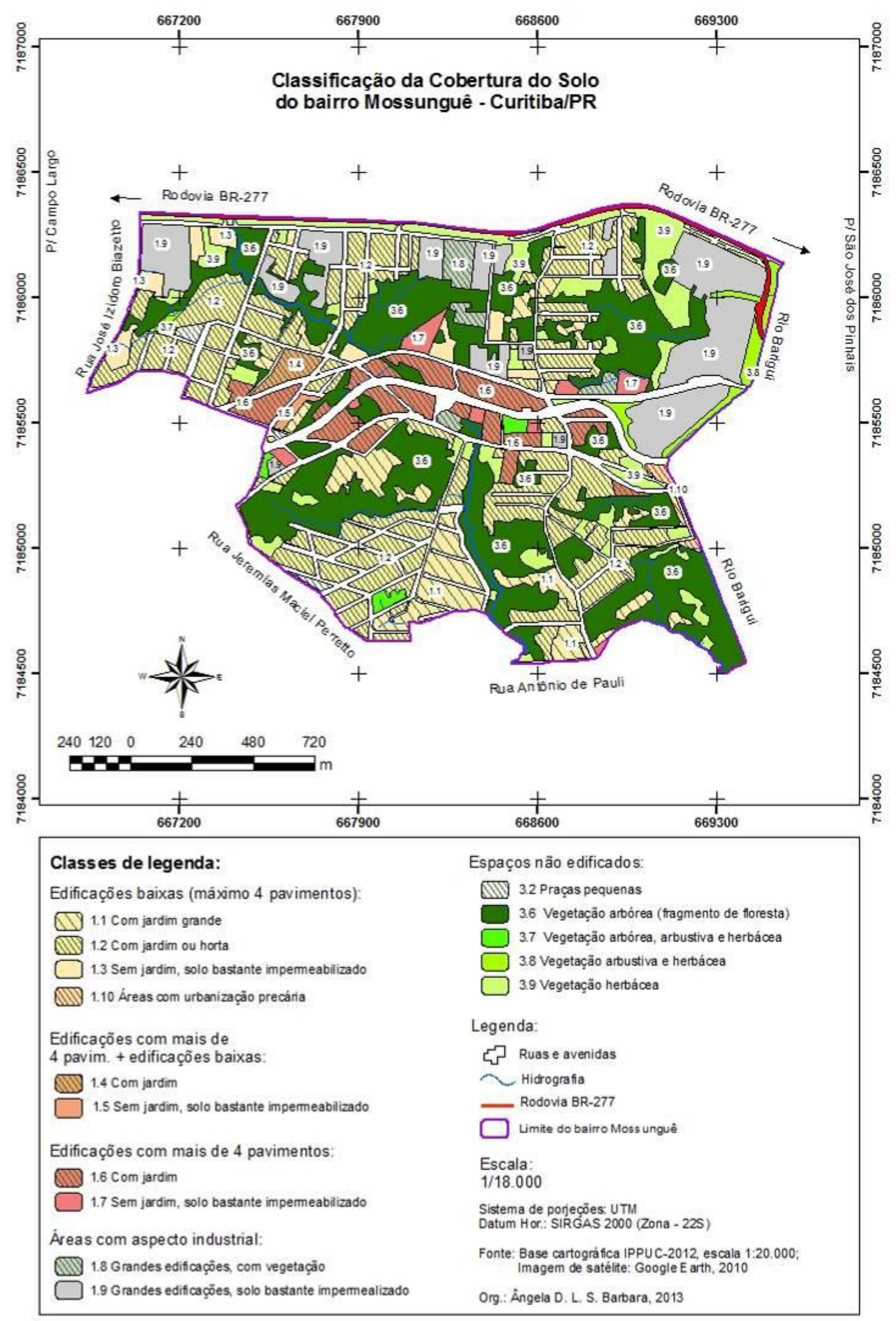

Figura 2: Mapeamento das unidades de paisagem do bairro Mossunguê. 


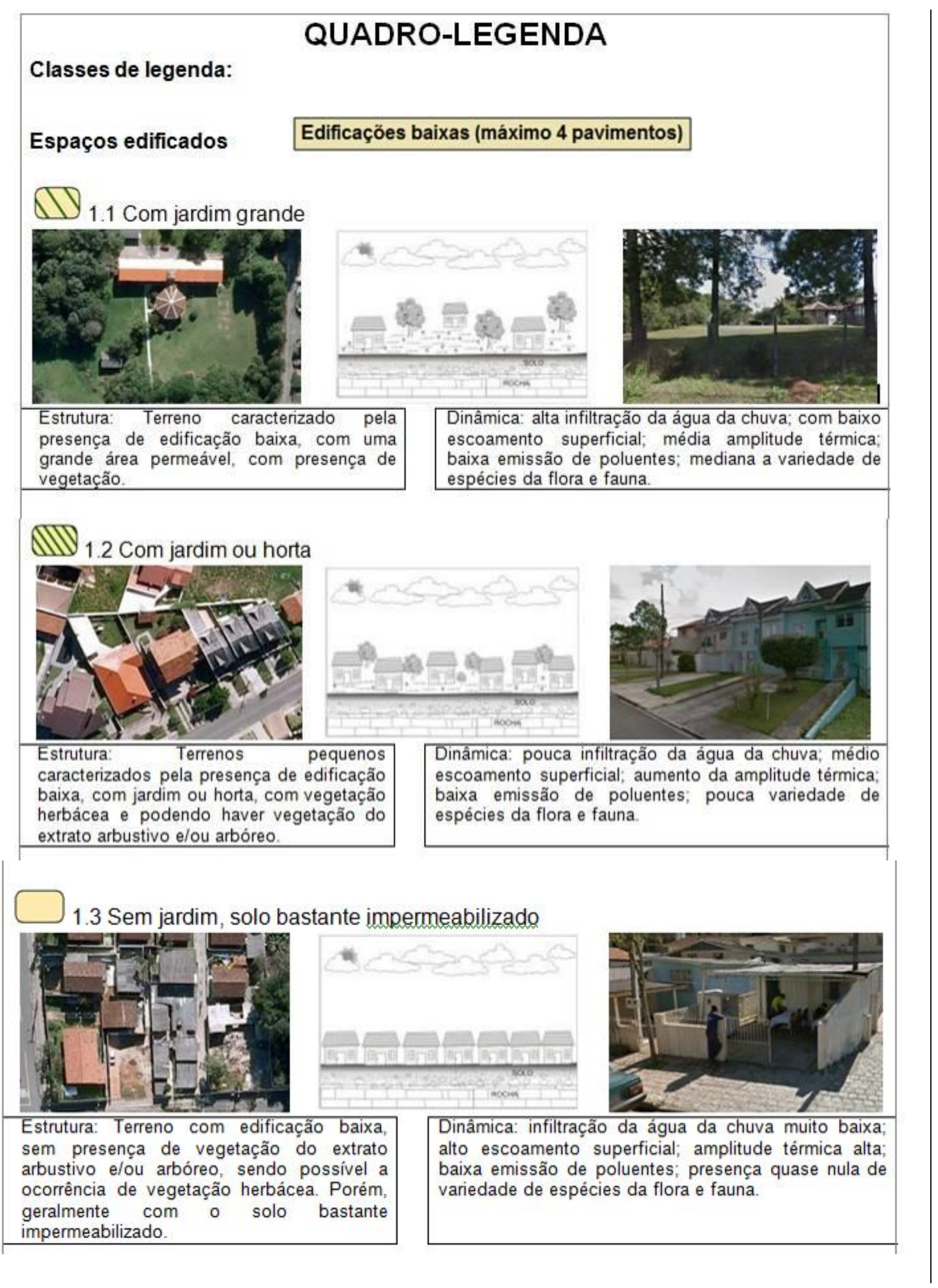

Figura 3a: Chave classificatória do mapeamento das unidades de paisagem do bairro Mossunguê. 


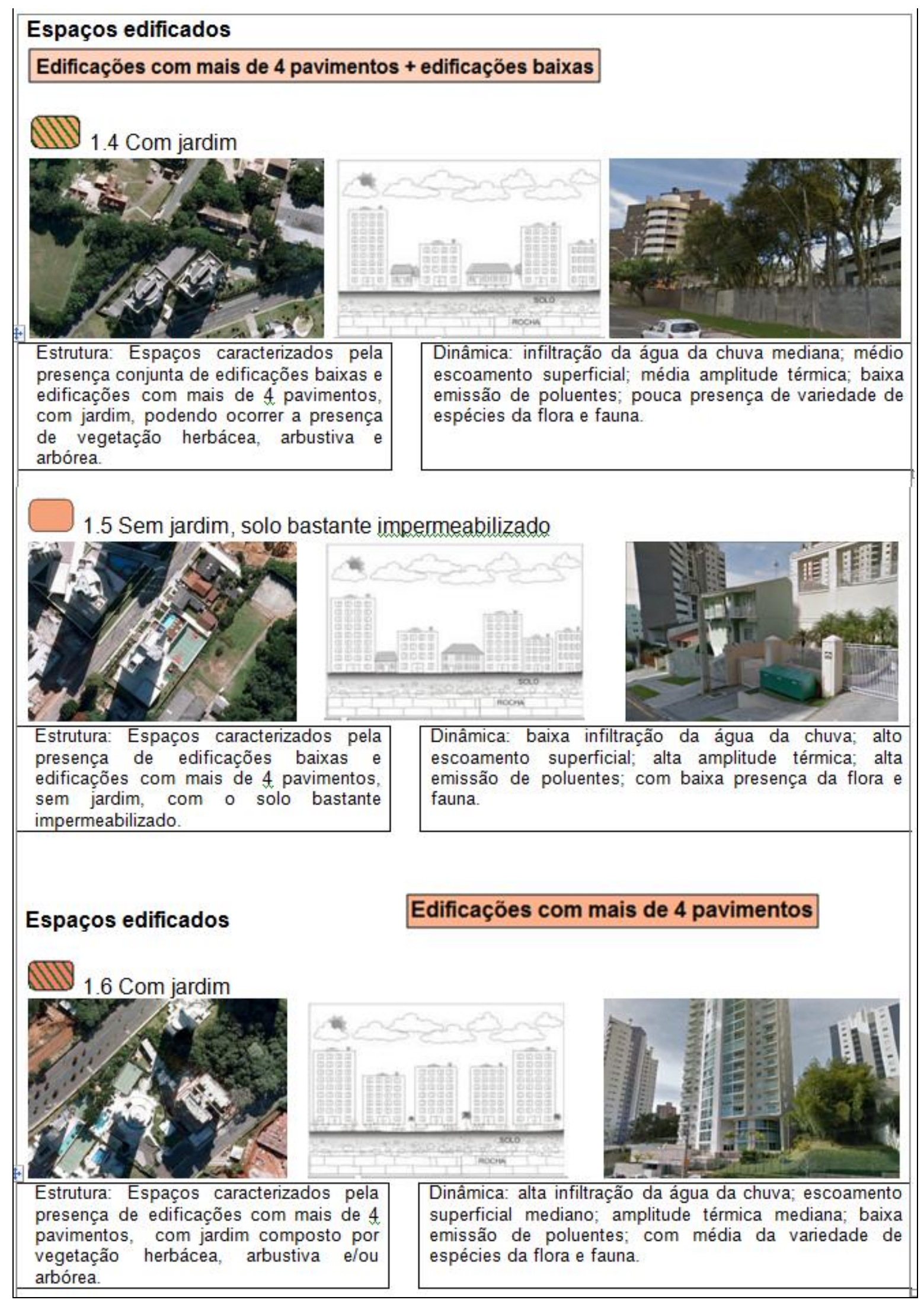

Figura 3b: Chave classificatória do mapeamento das unidades de paisagem do bairro Mossunguê. 


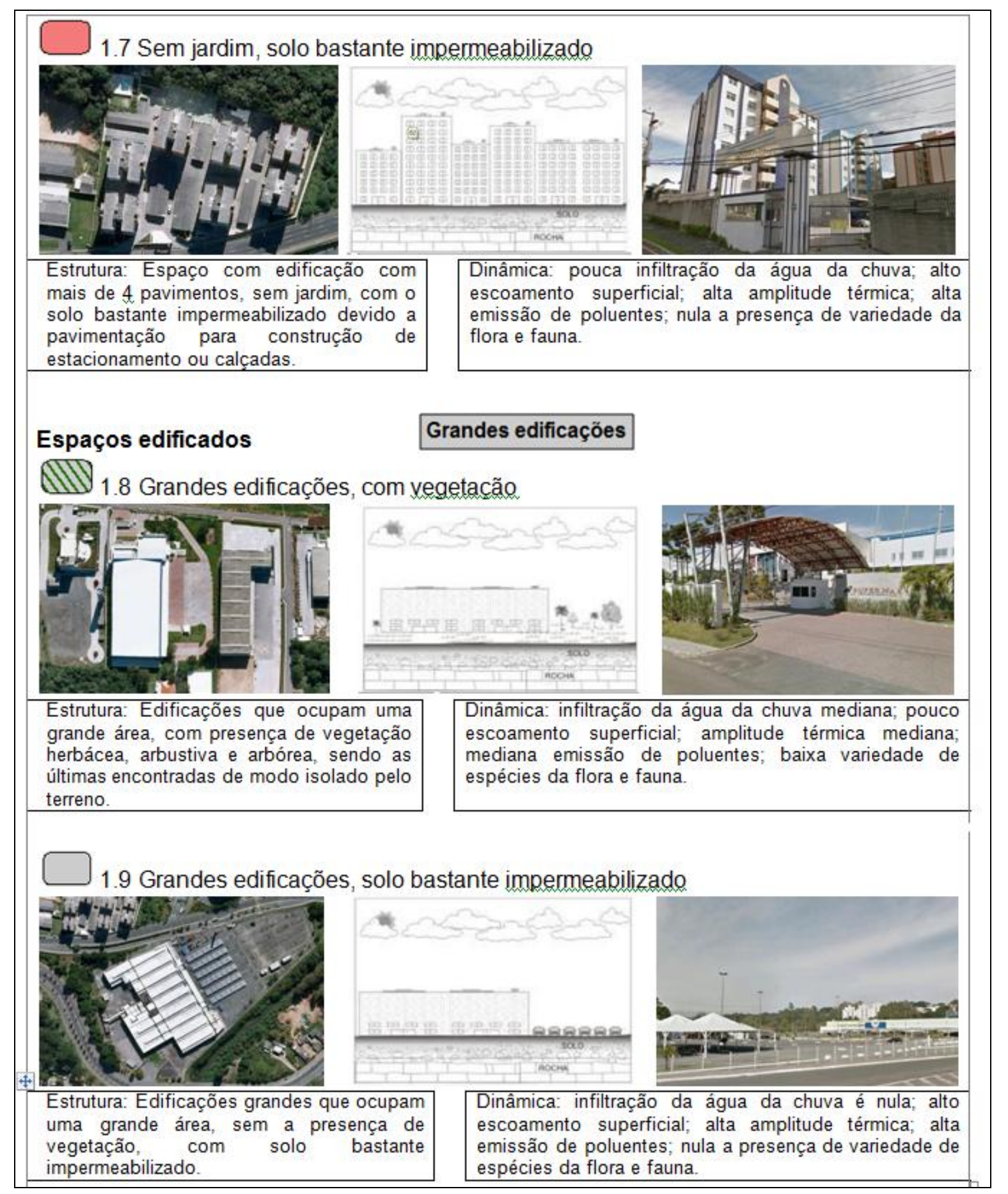

Figura 3c: Chave classificatória do mapeamento das unidades de paisagem do bairro Mossunguê. 


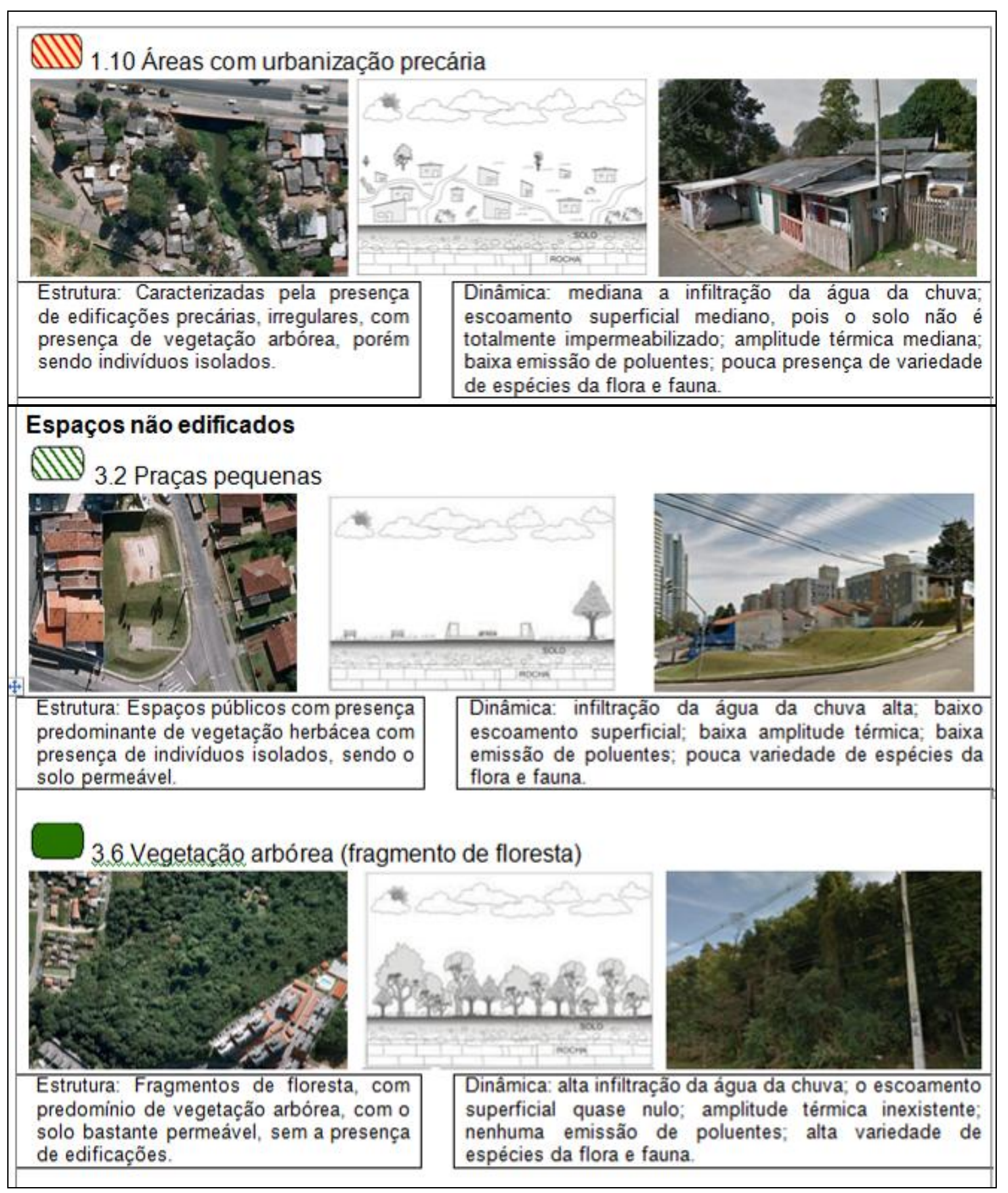

Figura 3d: Chave classificatória do mapeamento das unidades de paisagem do bairro Mossunguê. 


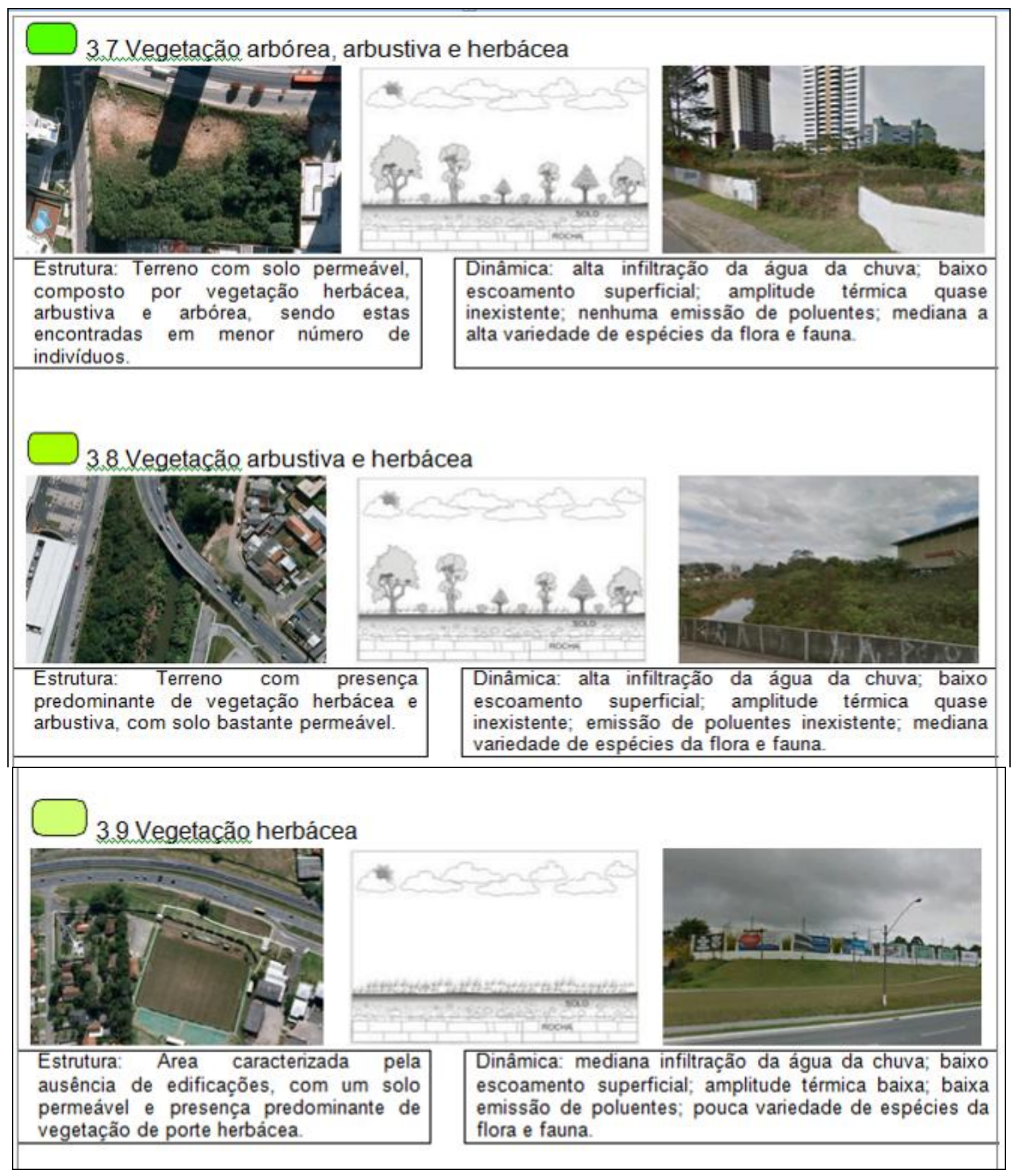

Figura 3e: Chave classificatória do mapeamento das unidades de paisagem do bairro Mossunguê. 
Com base no mapa de cobertura do solo (Figura 2) e na chave classificatória (Figura 3), as unidades de paisagens do bairro foram relacionadas a classes de hemerobia conforme apresenta a Figura 4.

\begin{tabular}{|c|c|c|c|c|c|c|c|}
\hline & \multicolumn{7}{|c|}{ Classes de Hemerobia } \\
\hline & Mínima & Muito baixa & Baixa & Média & Alta & Muito alta & Máxima \\
\hline \multirow{4}{*}{$\begin{array}{c}\text { Unidades } \\
\text { de } \\
\text { Paisagem }\end{array}$} & \multirow{4}{*}{$\begin{array}{l}\text { 3.6 Espaços sem } \\
\text { edificações - } \\
\text { Vegetação } \\
\text { arbórea } \\
\text { (fragmento de } \\
\text { floresta) }\end{array}$} & \multirow[t]{2}{*}{$\begin{array}{c}\text { 3.7 Espaços sem } \\
\text { edificações - } \\
\text { Vegetação } \\
\text { arbórea, arbustiva } \\
\text { e herbácea }\end{array}$} & \multirow[t]{2}{*}{$\begin{array}{l}\text { 3.2 Espaços } \\
\text { sem } \\
\text { edificações - } \\
\text { Praças } \\
\text { pequenas }\end{array}$} & \begin{tabular}{|c}
$\begin{array}{c}1.1 \text { Edificações baixas } \\
\text { (máx. } 4 \text { pavim.) - Com } \\
\text { jardim grande }\end{array}$ \\
$\begin{array}{c}\text { 1.2 Edificações baixas } \\
\text { (máx. } 4 \text { pavim.) - Com } \\
\text { jardim ou horta }\end{array}$
\end{tabular} & \multirow[t]{2}{*}{$\begin{array}{l}\text { 1.4 Edificações com } \\
\text { mais de } 4 \text { pavim. + } \\
\text { edificações baixas - } \\
\text { Com jardim }\end{array}$} & \multirow[t]{2}{*}{$\begin{array}{c}\text { 1.6 Edificações com } \\
\text { mais de } 4 \text { pavim. - } \\
\text { Com jardim }\end{array}$} & \multirow[t]{2}{*}{$\begin{array}{c}1.8 \text { Áreas com } \\
\text { aspecto industrial } \\
\text { Grandes } \\
\text { edificações, com } \\
\text { vegetação }\end{array}$} \\
\hline & & & & \multirow{2}{*}{$\begin{array}{l}\text { 1.3 Edificações baixas } \\
\text { (máx. } 4 \text { pavim.) - Sem } \\
\text { jardim, solo bastante } \\
\text { impermeabilizado }\end{array}$} & & & \\
\hline & & \multirow{2}{*}{$\begin{array}{c}3.8 \text { Espaços sem } \\
\text { edificações - } \\
\text { Vegetação } \\
\text { arbustiva e } \\
\text { herbácea }\end{array}$} & \multirow{2}{*}{$\begin{array}{l}\text { 3.9 Espaços } \\
\text { sem } \\
\text { edificações - } \\
\text { Vegetação } \\
\text { herbácea }\end{array}$} & & \multirow{2}{*}{$\begin{array}{l}\text { 1.5 Edificações com } \\
\text { mais de } 4 \text { pavim. + } \\
\text { edificações baixas - } \\
\text { Sem jardim, solo } \\
\text { bastante } \\
\text { impermeabilizado }\end{array}$} & \multirow{2}{*}{$\begin{array}{l}1.7 \text { Edificações com } \\
\text { mais de } 4 \text { pavim. - } \\
\text { Sem jardim, solo } \\
\text { bastante } \\
\text { impermeabilizado }\end{array}$} & \multirow{2}{*}{$\begin{array}{c}1.9 \text { Áreas com } \\
\text { aspecto industrial } \\
\text { Grandes } \\
\text { edificações, solo } \\
\text { bastante } \\
\text { impermealizado }\end{array}$} \\
\hline & & & & $\begin{array}{l}\text { 1.10 Edificações baixas } \\
\text { (máx. } 4 \text { pavim.) - Áreas } \\
\text { com urbanização } \\
\text { precária }\end{array}$ & & & \\
\hline
\end{tabular}

Figura 4: Classificação de hemerobia, segundo as unidades de paisagem.

Dado que algumas classes de unidades de paisagem (UP'S) possuem características semelhantes, optou-se por agrupar estas classes de unidades de paisagem em um mesmo grau de hemerobia.

Por exemplo, as áreas com aspecto industrial que são grandes edificações com vegetação ou com solo bastante impermeabilizado, foram agrupadas na classe de hemerobia "Máxima". Devido à grande área que estas unidades ocupam e a grande dependência energética e tecnológica necessárias ao seu funcionamento, não se poderiam agrupar "grandes edificações com jardim" com outras unidades de paisagem que possui menor demanda energética e tecnológica, como a UP "edificações baixas com jardim".

A Figura 5 apresenta o mapeamento do bairro de acordo com as classes de hemerobia que foram quantificadas e caracterizadas. 


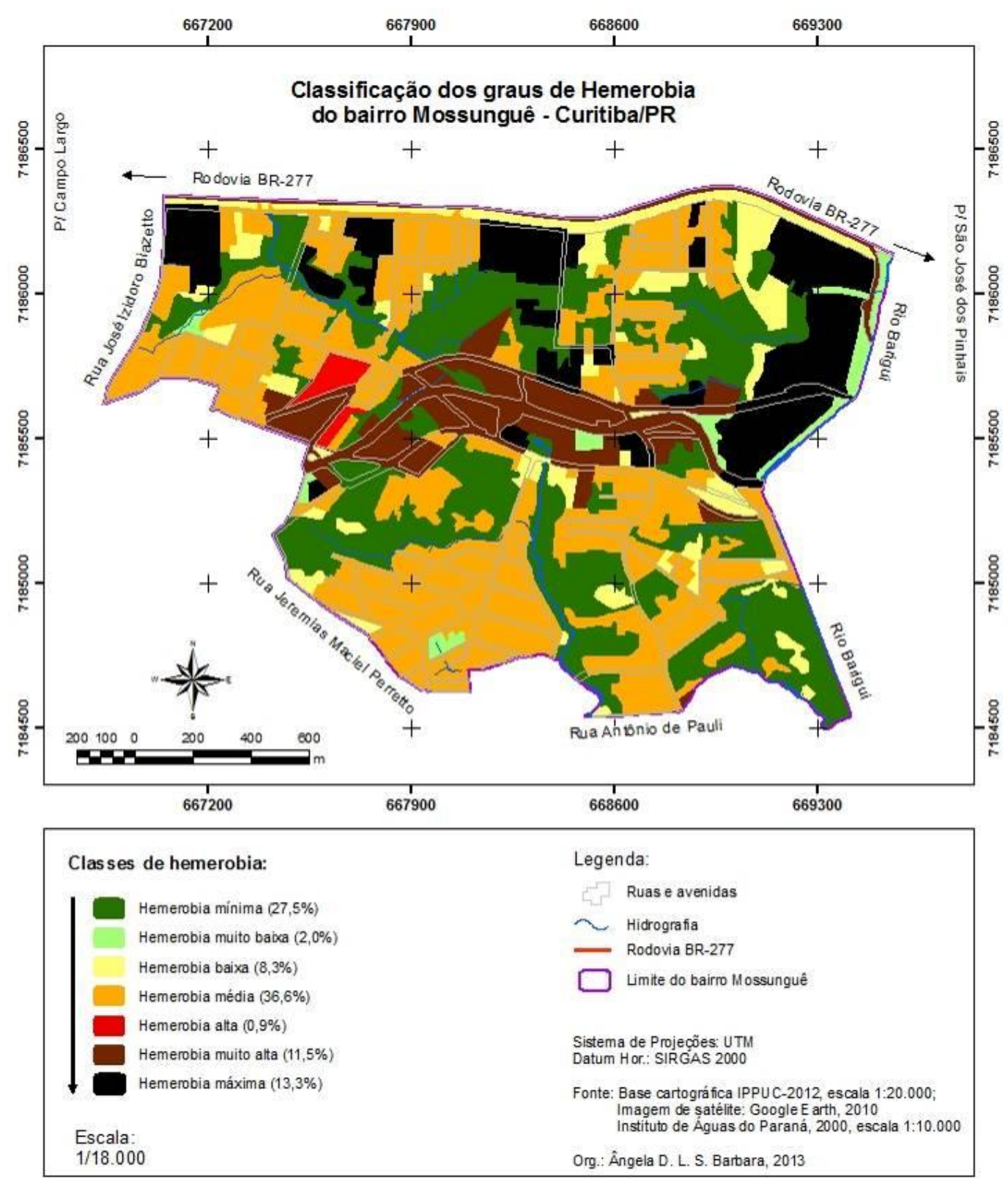

Figura 5: Classificação de hemerobia do bairro Mossunguê.

- Paisagem com hemerobia mínima (27,5\%): representada pela classe de vegetação arbórea (classe 3.6) constituída por fragmentos de floresta ombrófila mista, com presença de Araucaria angustifolia ocupando o dossel e de outros extratos arbóreos, além dos arbustivos e do herbáceo. Nota-se que os fragmentos se encontram principalmente junto aos rios que cortam o bairro. É uma paisagem que não depende de interferência externa para a sua manutenção, ou seja, não é dependente de tecnologia e nem de energia oriunda de combustíveis fósseis e nem de hidrelétricas, possuindo capacidade de auto regulação. 
- Paisagem com hemerobia muito baixa (2,0\%): compreende as classes de "vegetação arbórea, arbustiva e herbácea" e "vegetação arbustiva e herbácea" (classes 3.7 e 3.8). É uma paisagem que já sofreu a interferência humana, sendo pequenos fragmentos de vegetação, por vezes em condição de regeneração.

- Paisagem com hemerobia baixa (8,3\%): compreendendo as classes de pequenas praças e vegetação herbácea (3.2 e 3,9), são paisagens que passaram por interferência antrópica, apresentando plantas herbáceas ruderais e indivíduos arbóreos e arbustivos apenas de forma isolada; a vegetação é utilizada em um paisagismo que possui uma certa dependência energética e tecnológica para sua manutenção.

- Paisagem com hemerobia média (36,6\%): nessas paisagens já ocorrem os espaços edificados, sendo representadas pelas classes caracterizadas pela presença de edificações baixas (máximo 4 pavimentos): com jardim grande, com jardim ou horta, sem jardim, solo bastante impermeabilizado, áreas com urbanização precária. É uma classe que já sofreu bastante interferência humana e possui dependência energética e tecnológica para a sua manutenção. Nestas paisagens há pouca presença de vegetação de porte arbóreo, e quando presente, são indivíduos isolados.

- Paisagem com hemerobia alta (0,9\%): presença de edificações com mais de quatro pavimentos e edificações baixas (1.4 e 1.5), com jardim e sem jardim com solo bastante impermeabilizado, respectivamente. Poucos indivíduos de porte arbóreo e a vegetação herbácea é utilizada pelo paisagismo nos condomínios. Paisagem bem antropizada, com alta dependência energética e tecnológica necessárias para a sua manutenção.

- Paisagem com hemerobia muito alta (11,5\%): áreas com edificações de mais de quatro pavimentos com jardim e sem jardim com solo bastante impermeabilizado. Os tipos de vegetação presentes são implantados na paisagem visando, principalmente, a finalidade estética, por isso, também é uma paisagem com alta dependência energética e tecnológica. 
- Paisagem com hemerobia máxima (13,3\%): áreas com aspecto industrial, grandes edificações com vegetação e grandes edificações com solo bastante impermeabilizado. Pertence a esta classe o supermercado Carrefour, o Park Shopping Barigui e empresas localizadas na marginal da BR-277, bem como postos de combustível, que possuem grande dependência energética e tecnológica para sua manutenção.

Com a confecção dos mapas de unidades de paisagem e de hemerobia verificou-se que as áreas com maior hemerobia estão localizadas próximas à BR277. Essas áreas estão destinadas a Zona de Serviço (ZS-1) que "compreendem áreas ao longo de rodovias ou grandes eixos viários, destinadas à implantação de atividades comerciais e de serviços que, por seu porte ou natureza, exijam confinamento em áreas próprias ou sejam geradoras de tráfego pesado ou intenso", conforme Art. 8으, da Lei oㅜ 9.800, de 03 de janeiro de 2000 (IPPUC, 2013), que dispõe sobre o "Zoneamento, Uso e Ocupação do Solo no Município de Curitiba e dá outras providências" (CURITIBA, 2008).

A segunda maior categoria de hemerobia foi encontrada em áreas destinadas ao Setor Especial Nova Curitiba (SE-NC), que "constitui-se num eixo de desenvolvimento urbano de ocupação mista, localizado no prolongamento oeste do Setor Estrutural Norte, caracterizado por um sistema trinário conforme definido no $\S$ $1^{\circ}$ do art. 17 desta lei" (CURITIBA, 2008).

Assim, constatou-se uma relação direta entre as mais altas classes de hemerobia e essas duas zonas impactantes negativamente, mas previstas em lei, o que sugere estar havendo o cumprimento da legislação municipal de uso e ocupação do solo, pelo menos na área analisada. Salienta-se, porém, que essa lei não leva em consideração o aumento da hemerobia, ou seja, desconsidera questões importantes em relação à sustentabilidade das paisagens urbanizadas.

Esse fato pode ser comprovado, já que a própria lei de zoneamento sugere uma zona entre as duas anteriores que funcionaria como um tampão, ou seja, uma Zona de Transição Nova Curitiba (ZT-NC), que "compreendem áreas limítrofes à zoneamentos conflitantes, onde se pretende amenizar os impactos de uso e ocupação do solo" (CURITIBA, 2008), ou seja, áreas residenciais com o papel de 
amenizar os impactos dos usos abusivos e impactantes, liberados por lei, das áreas limítrofes.

Para o Instituto de Pesquisa e Planejamento de Curitiba (IPPUC, 2010), o bairro Mossunguê está entre os dez bairros que mais cresceram em termos populacionais, e que possuem os maiores índices de área verde por habitante, sendo que no período de $2000-2010$ o bairro teve um crescimento de $71,71 \%$ e possui $155 \mathrm{~m}^{2}$ de área verde por habitante.

Apesar de o bairro possuir este grande índice de área verde, são poucas as áreas destinadas ao uso público, portanto, esse índice de "área verde" pode estar relacionado a grandes superfícies cobertas por vegetação, encontradas em áreas públicas e privadas, e a baixa densidade demográfica e não a parques e bosques para o uso da população. Esse dado seria melhor categorizado se fosse apresentado com o conceito de "cobertura vegetal", conforme Cavalheiro, et al., 1999), ou seja, $155 \mathrm{~m}^{2}$ de cobertura vegetal por habitante.

Portanto, é preciso que a população cobre e o poder público invista na implantação sistemática no bairro Mossunguê de Espaços de Uso Público, Livres de Edificação e com Vegetação (EUPLEVs), conceito sugerido por Buccheri Filho (2012), recuperando áreas com vegetação herbácea, que já sofreram a interferência humana, transformando-as, por exemplo, em parques.

Além disso, a população deve se mobilizar para garantir que os quase $75 \%$ do bairro com hemerobia de média a baixa se mantenham para o bem de sua qualidade ambiental.

\section{CONCLUSÃO}

O bairro Mossunguê possui uma área de $3,38 \mathrm{~km}^{2}$ (IPPUC, 2009) sendo que deste total $2,52 \mathrm{~km}^{2}$ apresentam boa qualidade ambiental, pois apresenta $37,8 \%$ de sua área com hemerobia inferior à média e $36,6 \%$ de paisagem com hemerobia média, o que representa $74,4 \%$ da área total do bairro com cobertura vegetal e edificações abaixo de 4 pavimentos.

Apenas $25,6 \%$ da área total do bairro apresentam problemas com qualidade ambiental, pois apresentam pouca cobertura vegetal, com presença de edificações 
acima de 4 pavimentos, com solo muito impermeabilizado e também com presença de grandes edificações, como galpões, shopping e postos de combustível.

A classificação das unidades de paisagem com base na cobertura do solo e a chave classificatória configuraram-se em uma importante ferramenta para que fosse possível indicar os graus de hemerobia presentes no bairro Mossunguê, pois a chave classificatória permite uma clara visualização das paisagens por meio de várias perspectivas.

O conceito de hemerobia e o modo como foi aplicado, associados ao método desenvolvido por Valaski (2013), mostraram-se eficazes e didáticos, sugerindo uma utilização no entendimento da estrutura e dinâmica das paisagens para fins de facilitação da participação popular na tomada de decisões nos destinos das paisagens urbanizadas.

\section{REFERÊNCIAS}

BELEM, A. L. G.; NUCCI, J. C. Hemerobia das paisagens: conceito, classificação e aplicação no bairro Pici - Fortaleza - CE. RA'EGA 21 (2011), Curitiba: DGEOGUFPR.

BUCCHERI FILHO, A. T. O planejamento dos parques no município de Curitiba, PR: planejamento sistemático ou planejamento baseado em um modelo oportunista? Caminhos de Geografia, v. 13, n. 41 mar/2012 p. 206 - 222, Inst. de Geografia, UFU, Uberlândia, MG.

CAVAlHeIRO, F., NUCCI, J.C., GUZZO, P., ROCHA, Y.T. Proposição de terminologia para o verde urbano. Boletim da Sociedade Brasileira de Arborização Urbana, 3, jul/ago/set, 1999. Rio de Janeiro, RJ. Disponível em: www.geografia.ufpr.br/laboratorios/labs. Acesso em: 12.11.2013.

CURITIBA. Lei 9.800 e Leis complementares da Legislação de uso do solo. Prefeitura Municipal de Curitiba/IPPUC.

HABER, W. Using Landscape Ecology in Planning and Management. in: ZONNEVELD, I.S.; FORMAN, R.T.T.(Eds). Changing Landscapes: an ecological perspective. New York: Springer-Verlag, 1990. 286p.

HOUGH, M. Naturaleza y ciudad. Planificación y procesos ecológicos. Barcelona: Gustavo Gili, 1995, 315p.

IPPUC - Instituto Brasileiro de Geografia e Estatística-IBGE. Disponível em: http://www.ibge.gov.br/home/geociencias/geodesia/pmrg/faq.shtm\#6. Acesso em 18 de outubro de 2013. 
IPPUC - Instituto de Pesquisa e Planejamento Urbano de Curitiba-IPPUC. Censo 2010 - Análise dos bairros de Curitiba. Disponível em: http://www.ippuc.org.br/mostrarPagina.php?pagina=131. Acesso em 09 de outubro de 2013.

IPPUC - Instituto de Pesquisa e Planejamento Urbano de Curitiba-IPPUC. Curitiba em dados. Disponível em: http://curitibaemdados.ippuc.org.br/anexos/2009_Mapa\%20do\%20Bairro\%20Mossun gu\%C3\%AA.pdf. Acesso em 07 de outubro de 2013.

IPPUC - Instituto Paranaense de Desenvolvimento Econômico e Social-IPARDES Caderno estatístico município Curitiba, 2013. Disponível em: http://www.ipardes.gov.br/cadernos/Montapdf.php?Municipio=80000\&btOk=ok. Acesso em 07 de outubro de 2013.

KIEMSTEDT, H.; von HAAREN, C.; MÖNNECKE, M.; OTT, S. Landscape Planning. Contents and Procedures. Bonn: Federal Ministry for the Environment, Nature Conservation and Nuclear Safety, 1998.

MONTEIRO, C.A.F. Derivações antropogênicas dos geossistemas terrestres no Brasil ealterações climáticas: perspectivas urbanas e agrárias ao problema da elaboração de modelos de avaliação. SIMPÓSIO SOBRE A COMUNIDADE VEGETAL COMO UNIDADE BIOLÓGICA, TURÍSTICA E ECONÔMICA. Anais ... São Paulo: ACIESP noำ15, 1978, p. 43-74.

ODUM, E. P. Ecologia. Rio de Janeiro: Guanabara, 1983.

ROSS, J. Ecogeografia do Brasil: subsídios para planejamento ambiental. São Paulo: Oficina de Textos, 2009.

SAMPAIO, T. O tupi na geografia nacional. São Paulo: Nacional, 1987.

SUKOPP, H. Wandel von Flora und Vegetation in Mitteleuropa unter dem Einfluss dês Menschen. Berichte uber Landwitschaft, Bd. 50H.1: 112-139, 1972.

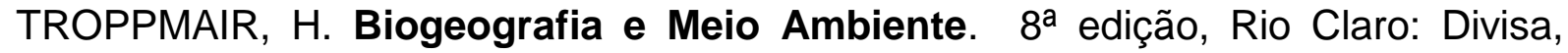
2008, 227 pgs.

VALASKI, S. Estrutura e dinâmica da paisagem: subsídios para a participação popular no desenvolvimento urbano do município de Curitiba-PR. Tese de doutoramento (Departamento de Geografia - UFPR), Curitiba, 2013.

AGRADECIMENTOS: Os autores agradecem o apoio financeiro do CNPq pela concessão das bolsas de doutorado ao segundo coautor e de produtividade em pesquisa ao terceiro coautor. 